\title{
Desobediência, Alargamento da Punição e Segurança Pública: Jovens Usuários de Drogas em Conflito com a Lei
}

\author{
Maria Eduarda Parizan Checa ${ }^{1}$ \\ ${ }^{1}$ Pontifícia Universidade Católica de São Paulo, SP, \\ Brasil. \\ ${ }^{1}$ Pontifícia Universidade Católica de São Paulo, SP, \\ Brasil. \\ Luis Henrique da Silva Sousa ${ }^{2}$ \\ Andrea Cristina Coelho Scisleski ${ }^{3}$ \\ ${ }^{2}$ Universidade Católica Dom Bosco, MS, Brasil. \\ ${ }^{3}$ Universidade Federal do Rio Grande do Sul, RS, Brasil. \\ Maria Júlia Dias ${ }^{2}$ \\ ${ }^{2}$ Universidade Católica Dom Bosco, MS, Brasil.
}

\begin{abstract}
Resumo: O objetivo deste artigo é problematizar o dispositivo de obediência, tomado neste texto como um articulador entre a moral cristã, o sistema jurídico-penal e a segurança pública no contexto da juventude em conflito com a lei. Discutimos aqui os efeitos que a produção de obediência assegura, em termos institucionais, para os jovens em conflito com a lei que cumprem medida socioeducativa de internação. Nesse cenário, chamamos a atenção especialmente para aqueles que são, simultaneamente, usuários de drogas e cometem ato infracional associado ao tráfico de drogas. A sobreposição dessas duas configurações implica em uma relação jurídicapenal que se alarga, a partir do dispositivo da obediência, como estratégia de governo para o possível cerceamento perpétuo da liberdade do jovem a outras instituições e saberes, que passam a atuar também em um viés policialesco. O referencial analítico que sustenta o presente trabalho parte da contribuição do pensamento foucaultiano ao campo da psicologia social.
\end{abstract}

Palavras-chave: Ato Infracional; Juventude; Tráfico de Drogas; Uso de Drogas; Obediência.

\section{Disobedience, Punishment Widening and Public Security: Young Drug Users in Conflit with the Law}

\begin{abstract}
This article intends to reflect the idea of disobedience, specially within the articulation between christianism and its morality, and a juridical-penal legislation that has some effects in public security, mainly in what refers to the youth in conflict with the law. Our starting point is Foucault's concept of device, discussing mostly the effects of an obeying production that intends to reach a parcel of the youth that is equally a drug user and has committed an infracional act associated with drug trafficking. In this matter, we focus our anaylisis in the youth that is complying educational correction measures. The ascension of both of theses aspects shapes the widening of a juridical-penal articulation that develops a type of government directed to this population, producing a policement way of thinking the practices that revolve them. In order to do so, we based our analysis in Foucault's epistemological point of view, as well as in social psychology studies.
\end{abstract}

Keywords: Infracional Act; Youth; Drug Trafficking; Drug Use; Obedience. 


\title{
Desobediencia, Ampliación de la Punición y Seguridad Pública: Jovenes Usuarios de Drogas en Conflicto con la Ley
}

\begin{abstract}
Resumen: El objetivo de este artículo es problematizar el precepto de obediencia, designado en este texto como un articulador entre la moral cristiana, el sistema jurídico-penal y la seguridad publica en el contexto de la juventud en conflicto con la ley. Analizamos aquí los efectos que la producción de obediencia garantiza, en termos institucionales, para los jóvenes en conflicto con ley que cumplen medida socioeducativa de internación. En este panorama, llamamos la atención especialmente para aquellos que son, simultáneamente, usuarios de drogas y cometen acto delictivo asociado al tráfico de drogas. La adición de estas dos configuraciones implican en una relación jurídico-penal que se amplía, a partir del precepto de la obediencia, como estratégica de gobierno para el posible cercenamiento perpetuo de la libertad del joven a otras instituciones y saberes, que pasan a actuar también en un sesgo policiaco. El referencial analítico que sostiene el presente trabajo parte de la contribución del pensamiento foucaultiano al campo de la Psicología social.
\end{abstract}

Palabras clave: Acto Delictivo; Juventud; Tráfico de Drogas; Uso de Drogas; Obediencia.

\section{Introdução}

Este artigo problematiza a articulação entre desobediência, práticas punitivas que se alargam para além do sistema prisional - que, no caso deste texto, ainda que mencione o sistema socioeducativo, foca-se em suas amarrações com a questão da segurança pública - especialmente no caso de uso de drogas de jovens em conflito com a lei. Discute-se como categorias que são postas e tratadas separadamente perante a lei entrelaçam-se quando se conectam com essa juventude, tendo como efeito o alargamento de práticas punitivas, uma vez que os usuários de drogas vão ser tratados como dependentes químicos e os traficantes como criminosos.

É sabido que a Lei ${ }^{\circ} 11.343 / 2006$ não apresenta uma indicação quantitativa de droga entre o que vem a ser considerado porte para consumo próprio (uso) e para venda (tráfico). Contudo, as ações das autoridades são bastante objetivas quando se trata de um usuário pobre, posto que muitos jovens traficam também para custear o próprio vício (Scisleski, Reis, Hadler, Weigert, \& Guareschi, 2012), a partir do tratamento como criminoso. Essa é uma das situações mais comumente encontradas nas Unidades Socioeducativas de Internação (UNEI) no Brasil e nos trâmites da justiça no que se refere aos jovens em conflito com a lei (Conselho Nacional de Justiça, 2012), e que também tem sido encontradas no panorama do sistema prisional adulto (Conselho Nacional do Ministé- rio Público, 2016). Nesse caso, os jovens são na maior parte das vezes considerados traficantes e recebem penalidades referentes a tal ato infracional; ou seja, eles são tomados pelo judiciário a partir do momento em que entram para a criminalidade, ou, como queremos enfatizar neste artigo, a partir do momento em que são considerados (des)obedientes em relação às leis. Assim, este artigo pretende problematizar como ocorre a captura desses sujeitos pelo judiciário, a partir de um dispositivo de (des)obediência que se forja na maneira como são dados os circuitos desses jovens pelo paradigma médico-jurídico de cumprimento de medida de internação em estabelecimentos como UNEI e Comunidades Terapêuticas. Ou seja, o foco aqui reside não no sistema socioeducativo, mas na operação de como esse dispositivo de obediência baliza práticas que alargam ou restringem a punição na ordem da segurança pública.

\section{Entrelaçamentos entre desobediência e segurança pública}

Vimos, com Foucault (2010), que a formação do sistema judiciário e, por sua vez, do sistema punitivo (Foucault, 2015), reafirma o modelo cristão postulado a partir de um forte compromisso com práticas de obediência e de produção de verdade. A genealogia do sistema prisional se conecta às práticas cristãs (Foucault, 2015). Enquanto campo de formação, isso se dava inicialmente pelo sistema de entrada e per- 
manência dos monges cristãos nos monastérios. Isso ocorria da seguinte forma: os indivíduos que desejavam tornarem-se monges deveriam entender que a obediência era a característica mais valorizada nos monastérios, ainda que houvesse consciência do fato de que essa direção nunca os levaria a um estado em que não necessitassem mais de um diretor, de forma que teriam de praticar sempre essa obediência. Outro aspecto importante é que essa obediência tinha um fim em si mesma; ou seja, não importava o tipo de ordem ou a vontade do dirigido, ele precisava obedecer apenas pelo ato da obediência em si ser considerada uma virtude. Em outras palavras, a obediência era sempre o fator mais importante e valorizado nos monastérios.

Para Foucault (2010), esse modus operandi do cristianismo não qualificava as ações como boas ou más - como fazia o modelo grego de direção - mas os sujeitos. Dessa forma, o sujeito (bom ou mau), aparecia como fator modificador da ação, tornando-a boa ou má. Isso implica dizer, dentro desse contexto, que um sujeito era considerado bom ao obedecer e, consequentemente, mau ao desobedecer.

Se pensarmos a partir de uma perspectiva de continuidade-descontinuidade que assinala o pensamento foucaultiano, as práticas ocidentais que geraram o sistema judiciário herdam, em sua base, uma importante relação com a obediência. Foucault (2009) entende o direito como um sistema no qual se fomenta a sujeição, um sistema de relações de poder pautadas em um discurso da verdade, para o qual não há saída: ou se é culpado ou inocente; isto é, opera-se aqui com o imperativo dos absolutos.

Pesquisadores que atuam no campo do sistema socioeducativo (Nascimento, 2002; Rizzini, \& Pilloti, 2009; Scisleski et al., 2012), tratando-se da produção de sujeição sobre as formas de ser jovem, destacam que pelo fato de ser incumbido sobre esse sujeito projeções de progresso, que se atrelam com frequência ao conceito de desenvolvimento, surge, consequentemente, uma rede que procura regulamentar a vida desses sujeitos. Com isso, aqueles que são considerados desviantes da norma têm certas formas de sujeição que são produzidas por meio de regimes de verdade que se estabelecem sobre a forma como esses sujeitos devem agir; isto é, espera-se deles uma relação positiva com a questão da obediência.

No contexto do sistema prisional adultos, a relação com a obediência também se mantém, uma vez que o bom comportamento, geralmente relativo ao acato das ordens das figuras de autoridade contribuem para a progressão do regime de cumprimento da pena, do mesmo modo que a desobediência acarreta em efeitos que podem desencadear na sua regressão de regime, alargando o tempo de prisão do detento (Carvalho, 2008; Zaffaroni, \& Pierangeli, 2008).

Um exemplo bastante relevante e contundente à argumentação que aqui sustentamos refere-se à própria configuração da sala de audiência dos tribunais, como se vê em diversos tribunais penais no Brasil. A arquitetura do local já conota o seu objetivo discursivo - as condições de fala e da produção da verdade - a partir da elevação física do espaço aonde se situa a figura do juiz, que se sobressalta sobre as outras. $\mathrm{O}$ confronto que é estabelecido à figura do réu, geralmente em posição de desnível inferior à figura do magistrado, a promessa que é feita antes do interrogatório em dizer a verdade, a obediência em responder as perguntas que são elaboradas, estrategicamente, para extrair e capturar a verdade daquele que está sendo julgado, enfim, um cenário que exprime de antemão o próprio alargamento das estratégias punitivas àquele que está diante da imponência jurídica (Scisleski, \& Guareschi, 2011). Percebemos aí, também, os resquícios de um cristianismo que se atualiza vinculando obediência não apenas dos atos, mas do sujeito, a uma autoridade, não divina, mas jurídica, policial e penal.

Segundo Foucault (2010), no que tange a esse sistema cristão de direção e obediência, que deu condições de possibilidade para a emergência de um sistema punitivo jurídico-penal, os dirigidos são ensinados a não esconderem, em hipótese alguma, os seus pensamentos. Não é apenas importante dizer o que foi feito e como foi feito, mas se havia a intenção de fazê-lo.

Porém, para Foucault (2008a), essa busca pela verdade não se dá apenas pelo judiciário, mas, paulatinamente imiscui-se e articula-se a outros saberes. $\mathrm{O}$ alargamento da função de polícia, por exemplo, debatida pelo próprio Foucault (2008b) a partir do conceito de dispositivo de segurança - que, resumidamente, implica em dizer que faz a gestão da circulação de pessoas e objetos, interditando-os ou incentivando a movimentar-se - estende-se também a uma diversidade de saberes que passam, de certa forma, a exercer uma função policialesca. Dentre esses saberes, podemos destacar o próprio discurso científico de uma maneira geral, discurso esse que se estende às escolas, 
hospitais e outras várias instituições que têm como fim a fabricação de um indivíduo docilizado. Ou seja, há uma ideia de compromisso com a verdade ligada à lógica da obediência, como um todo. Subjaz aí a ideia de uma normalidade relacionada a uma lógica obediente: o bom aluno obedece ao professor; o bom paciente conta a verdade para seu médico e obedece $o$ tratamento; no caso de um jovem em medida de internação, ser obediente às normas institucionais conta como um importante sinalizador para a sua progressão de medida; no caso do preso adulto, essa obediência também contribui para sua progressão de regime de cumprimento de pena.

Deter-nos-emos, agora, aos jovens usuários de droga que entram em conflito com a lei - pensados aqui na discussão da lógica da racionalidade do sistema prisional e na articulação com a segurança pública -, isto é, como aqueles sobre os quais a droga opera como um dispositivo que serve como justificativa para que eles circulem pelos trâmites da justiça, a partir do momento em que esse uso de droga conduz para o cometimento de ato infracional, visto que é a partir do ato infracional, da desobediência à lei e não diretamente do uso de droga - que o jovem é capturado. Para esses, não há intervenção jurídica ou ação preventiva de Políticas Públicas que os leve para um caminho diferente das medidas de internação em UNEI ou Comunidades Terapêuticas. Assim, podemos dizer que o uso de droga desses sujeitos passa a ter importância para o Estado a partir do momento em que opera como um dispositivo que leva ao ato infracional. Ressaltamos que o emprego do termo (des) obediência refere-se ao dispositivo que captura e gere a vida dessa população em relação à intervenção jurídica sobre o uso de drogas: a infração à lei em função de custear o uso de drogas é tomada como uma desobediência pelo Estado e, a partir disso, esse jovem é inserido em um sistema de medidas que fomentam a produção de submissão, de docilização, já que é a obediência à lei é um dispositivo que os leva à possibilidade de progressão da medida, sua "suavização" ou até mesmo sua suspensão.

Cabe destacar aqui que se entende por dispositivo, a partir da leitura que Agamben (2009) faz de Foucault (1994), qualquer coisa que está sempre ligada à ideia de gestão; ou seja, o recurso de pôr em circulação objetos variados - mercadorias, saúde, trabalho, prisões, idade, certificados etc.; enfim, tudo o que se pode tornar alvo de manejo para gerir a vida da população - são dispositivos. Ressaltando: existem tantos dispositivos quanto pudermos criar com o objetivo fim de gerir a população. Dessa forma, a ideia de dispositivo (Agamben, 2009) destaca também um determinado contexto histórico e, por isso, está ligado à ideia de movimento, de arranjos que se fazem e se desfazem no decorrer do tempo. Sobretudo, é fundamental levar em conta que o dispositivo é também um descritor das relações de poder; é ele que sinaliza como o poder opera. Assim, a leitura que Agamben (2009) faz desse conceito foucaltiano entende que o dispositivo é a rede que articula os movimentos de poder, tendo, por isso, uma função estratégica alinhada à concepção de governo, uma vez que sinaliza como ocorrem os movimentos das relações de poder.

Dessa forma, a ideia da (des)obediência como dispositivo está ligada a isso que aparece como sinalizador do paradoxo do sistema jurídico que impele esses jovens a cometerem atos infracionais. Esses jovens, embora muitos sejam dependentes químicos e necessitem de tratamento sanitário para tanto, são tomados pelo judiciário como traficantes e sua condição de usuário de drogas é substituída e menosprezada em relação à condição de traficante. O judiciário os captura e os abandona simultaneamente, os captura pelo delito e os abandona a mercê do uso de drogas, numa lógica cristã em que a obediência configura um caminho para a salvação. E, se o sujeito não obedece, ele é mau, tem má índole, ou algum transtorno de personalidade e pode causar perigo à sociedade e, por isso, deve permanecer em medida de internação. Nesse contexto, ficam claras as condições de possibilidade que permitem o surgimento e a proliferação de inúmeras fazendas e comunidades terapêuticas, geralmente de cunho religioso, que prometem uma reforma na alma desses jovens. A desobediência como dispositivo expressa aqui, portanto, o alargamento de práticas punitivas que se alastram na lógica da segurança.

\section{Crime e uso de drogas: amarrações entre punição e segurança pública}

Atualmente, sabemos que a maior parte dos indivíduos que compõem o segmento de jovens marginalizados e usuários de drogas é pobre e de baixa escolaridade, de acordo com o Panorama Nacional: a execução das medidas socioeducativas de internação (Brasil, 2012). Tal situação nos permite entender os parâmetros de um racismo de Estado, porém, com 
uma diferença: há um dispositivo legal que deveria promover saúde e socialização desses jovens. De acordo com o Estatuto da Criança e do Adolescente (Lei No 8.069, 1990), crianças e adolescentes devem ser vistos perante à lei como sujeitos de direito que, portanto, devem ser protegidos pelo Estado, de forma a garantir que esses indivíduos se desenvolvam física, mental, espiritual e socialmente, em condições dignas de liberdade.

Contudo, o que vemos é que a doutrina da proteção integral, consagrada pelo Estatuto da Criança e do Adolescente (Lei No 8.069, 1990), ainda está longe de ser colocada em prática. Observamos que, de acordo com Agamben (2004), essa condição de suspensão ou enfraquecimento da eficácia da lei é o que faz com que medidas com força-de-lei sejam aplicadas no espaço que é aberto com a desaplicação daquelas que deveriam, teoricamente, estar em vigor. Esse movimento torna legal aquilo que não é, tecnicamente, legal e, em alguns casos, isso leva à exclusão de grupos de pessoas da proteção da própria lei, mesmo quando essa proteção é prevista por lei (Agamben, 2004). Sendo assim, é gerado um sistema em que a própria lei é usada como condição para sua anulação, acobertando o poder de um decisionismo jurídico e evidenciando não apenas a diferença, mas o paradoxo existente entre decisão e legislação.

Esse decisionismo ocorre, primeiramente, por parte dos policiais, quando encontram um jovem com determinada quantidade de droga, por exemplo, e o consideram traficante. Como já referimos anteriormente, uma vez que não há prescrição quantitativa sobre o que é definido como porte de drogas em termos de tráfico, a própria legislação acaba deixando margem para essa decisão à polícia, que determina a finalidade da droga de acordo com a sua natureza e o contexto social da situação de apreensão da substância (Brasil, 2006).

Depois, o decisionismo ocorre por parte dos operadores do direito, que primam pela segurança da população e ignoram os preceitos fundamentais do Estatuto da Criança e do Adolescente (ECA) e, dessa forma, sancionam uma medida de internação em uma UNEI, onde o jovem ficará por um tempo com sua liberdade restrita e sem atendimento à saúde devidamente. Essa negligência com a saúde dos jovens internados é descrita, dentre outros possíveis documento, no relatório da Comissão de Direitos Humanos OAB/ MS Ricardo Brandão (Mato Grosso do Sul, 2014). No referido relatório, há menção à ausência de profissionais e de espaços minimamente equipados para serviços simples, como é o caso de atendimento de assepsia para ferimentos, por exemplos. Ou mesmo o não uso do espaço de refeitório, que apesar de existente, não é utilizado no local; as refeições são feitas nos "quartos" dos jovens, sob a alegação de prevenir possíveis motins.

Uma alternativa que está sendo muito utilizada atualmente no contexto de Campo Grande/MS, e que se alinha ao panorama nacional, é o envio dos jovens a Comunidades Terapêuticas, como espaço para cumprimento de medida de internação. Cabe enfatizar que quase sempre nesses espaços tudo gira em torno de fatores religiosos, muitas vezes radicais, na qual o sujeito também terá, além da sua liberdade restrita, certa obrigação a aceitar certos dogmas em prol de uma suposta abstinência total do uso de drogas como cura. Aqui, vemos o atrelamento não apenas da patologia (dependência química) ao crime (ato infracional), mas a formação de uma tríade moral que articula patologia, crime e pecado (falta da crença em deus e nos princípios cristãos).

Tendo em mente esse cenário, perguntamos: o que UNEI e as Comunidades Terapêuticas têm em comum? A começar pelo fato de ambas se localizarem em lugares distantes do centro da cidade - fato que já foi discutido por Foucault (2005) quando apresenta a ideia de instituições de sequestro -, essas que, por sua vez, têm como objetivo afastar um grupo que é considerado perigoso para a sociedade, colocando-o em lugares afastados, nos quais o objetivo maior é “[...] deixar morrer" (Foucault, 2005, p. 287), para que o resto da sociedade possa ter uma determinada qualidade de vida, mantendo assim uma certa tranquilidade social. Outro fator importante que esses lugares têm em comum é a falta de assistência devida, de acordo com as exigências do ECA. Primeiramente porque nas UNEI a quantidade de profissionais especializados não é o suficiente para atender toda a população de jovens que lá cumprem medida, fazendo com que o PIA (Plano Individual de Atendimento) não seja cumprido na maior parte das vezes, além das condições insalubres em que a maior parte desses lugares se encontra (Brasil, 2012; Scisleski, Concentino, \& Galeano, 2017).

Foucault (2008b) nos ajuda a pensar sobre as tecnologias que são investidas em certas populações para discipliná-las. Tais tecnologias disciplinares são dire- 
cionadas tanto para grupos com potencial para contribuir com o progresso da sociedade, tanto para aqueles com potencial para retardar esse progresso. Por isso, são feitas cisões que operam para separar a sociedade em grupos e direcionar a eles diferentes tipos de investimento. A partir disso, ocorre, de acordo com Foucault (2008b), o racismo de Estado, que o autor define como "[...] o meio de introduzir afinal, nesse domínio da vida do qual o poder se incumbiu, um corte: o corte entre o que deve viver e o que deve morrer" (Foucault, 2008b, p. 304). Tal corte se dá numa relação estratégica de governo que se exerce entre as duas partes: os que devem morrer são dizimados para melhorar a qualidade de vida daqueles que devem viver.

Em relação às comunidades terapêuticas, a maior parte delas segue um plano religioso de salvação dos jovens usuários de drogas. Em entrevista com uma psicóloga do fórum que atua no Fórum em Campo Grande/MS, a maior parte desses lugares não conta com o suporte de profissionais da saúde e da assistência social para acompanhar os jovens. Além disso, o Conselho Federal de Psicologia (CFP) e o Conselho Federal de Serviço Social (CFESS) manifestaram-se contrários às práticas que são comumente exercidas nas Comunidades Terapêuticas, listando as violações de direitos que ocorrem nesses lugares: violências, castigos, desrespeito à orientação sexual, imposição religiosa, violação de privacidade, entre outras (Conselho Federal de Psicologia, 2015). No referido documento produzido pelo CFP (2015), destaca-se ainda que o tratamento utilizado nesses lugares baseia-se numa culpabilização e inferiorização do usuário de drogas, que passa a ter o uso de drogas substituído por uma submissão institucional e ideal a uma determinada corrente religiosa - usualmente cristã - e restringindo obrigatoriamente as práticas religiosas desses usuários às práticas condizentes com o segmento religioso do local. "Isso se deve ao fato de que o Estado Moderno Ocidental integrou, numa nova fórmula de política, uma antiga tecnologia de poder, originada nas instituições cristãs. Podemos chamar essa tecnologia de poder pastoral" (Foucault, op. cit. Dreyfus \& Rabinow, 2010, p. 236).

O poder pastoral tem o objetivo de assegurar a salvação individual em outro nível de realidade. Demanda, por isso, que haja uma preparação caso seja necessário sacrificar-se pela vida e pela salvação do rebanho. O pastor cuida da comunidade como todo e de cada indivíduo dentro dela e, para isso, pre- cisa conhecer cada membro, sua mente, alma etc. Por isso o poder pastoral implica numa direção da consciência. (Dreyfus, \& Rabinow, 2010).

É notória, por meio da efetivação das ações realizadas pelas Comunidades Terapêuticas, a apropriação que é feita de dogmas cristãos de obediência e compromisso com a verdade inseridos dentro daquilo que acaba se consolidando como uma técnica de gestão direcionada ao uso de drogas desse sujeito que é usuário e encontra-se em conflito com a lei. Porém, não há nenhum dispositivo legal no Estatuto da Criança e do Adolescente que legitime tal técnica, o que configura isso dentro da lógica já abordada do decisicionismo e que permite a emergência de um exercício para além do aparato legal (Agamben, 2004).

Além disso, de acordo com Trevisani (2013), a partir de uma pesquisa nos documentos arquivados sobre as internações no Hospital Psiquiátrico São Pedro no início do século passado, foi observado que os diferentes tipos psicossociais que compõem o território da loucura mudam juntamente com o tempo, mas o tema da loucura continua presente nas internações atuais. É possível entender que as clínicas psiquiátricas e, especialmente, as comunidades terapêuticas, que atualmente trabalham com uma grande demanda de usuários de droga, constituindo o espaço desse campo da anormalidade que constitui a loucura ainda hoje, mesmo com algumas mudanças do que define o paradigma loucura, ao passo que produzem a patologização e o tabu moral em torno da questão dos usuários de droga. Pode-se dizer, assim, que a lógica manicomial é reaproveitada por esse tipo de prática, em qual ainda opera em vigor uma importante relação com a obediência.

\section{O traficante-usuário: a dupla marginalização no sistema jurídico-penal}

De acordo com Tiburi e Dias (2013, p. 87):

Que se possa dizer que existe um "dispositivo das drogas" significa, nesse caso, que se disputa a verdade sobre as drogas num "campo de forças" e que é essa verdade que vem regular seu uso, o comportamento em torno dela, inclusive daquilo que o senso comum chama de vício.

As autoras (Tiburi, \& Dias, 2013), afirmam que o "corpo-drogado" sofre uma violenta estigmatização, 
tanto política, quanto moral. Trata-se de um corpo que, não obstante o fato de estar vivo, é desqualificado em sua condição de vida, temido pelo peso do moralismo, o que o leva ao abandono enquanto sujeito pela sociedade e enquanto cidadão pelo Estado.

Essas produções de verdade, que sustentam as práticas de abandono - não apenas social, mas também jurídico (uma vez que as leis podem, em termos práticos, serem relativizadas e, portanto, efetivadas ou não) -, são entendidas por Foucault (2002) como formas que a sociedade encontrou de organizar as suas ações, a partir da subordinação a um discurso que sustenta e autoriza essas práticas:

As práticas judiciárias - a maneira pela qual, entre os homens, se arbitram os danos e as responsabilidades, o modo pelo qual, na história do Ocidente, se concebeu e se definiu a maneira como os homens podiam ser julgados em função dos erros que haviam cometido, a maneira como se impôs a determinados indivíduos a reparação de algumas de suas ações e a punição de outras, todas essas regras ou, se quiserem, todas essas práticas regulares, é claro, mas também modificadas sem cessar através da história - me parecem uma das formas pelas quais nossa sociedade definiu tipos de subjetividade, formas de saber e, por conseguinte, relações entre o homem e a verdade que merecem ser estudadas (Foucault, 2002, p. 11).

Dessa forma, ao optar pelo termo "usuário de droga" no lugar de "dependente químico", a intenção posta é a de evidenciar o teor de vigília, de controle que o termo "dependência" designa e, também, de questionar certos regimes de verdade que reduzem o uso de drogas sempre a um vício e a uma consequente patologização. Tiburi e Dias (2013) insistem na necessidade de evidenciar a disparidade entre uso e vício, uma vez que é pelo pretexto do temor moral à dependência que se operacionalizam práticas invasivas e, muitas vezes, violentas a esses sujeitos. Ou seja, duplicamos os danos desse pensamento em relação aos jovens ao postular os efeitos sobre um indivíduo que sofre duas vezes esse processo de marginalização: usuário (pobre) de drogas e tendo cometido ato infracional, o jovem se insere numa subcategoria da categoria de marginalidade - ato infracional e uso de drogas, tornando-se, a partir dessa dupla sobreposição, mais vulnerável a tais danos.
Atualmente, como já citado, há a distinção das medidas para aqueles que apenas fazem uso de substâncias ilícitas e para aqueles que traficam para manter o uso:

Quando se fala em políticas sobre drogas, comumente se faz uma distinção entre os usuários, de um lado, e os traficantes que comercializam as substâncias ilícitas, de outro. No primeiro caso, o sujeito é considerado doente, necessitando de ajuda médica e psicossocial; já o segundo caso, o sujeito é tido como um criminoso, merecedor de sanções penais provenientes do Estado. Parece um exercício simples essa diferenciação. Porém, nessa polarização entre usuário de drogas e traficante, não há nenhum debate que questione a situação dos usuários pobres que, para custear o vício, atuem no tráfico (Scisleski, Silva, Galeano, Caetano, \& Bruno, 2013, p. 114).

De acordo com Joia (2014), foi no final da década de 30 que, no Brasil, o porte de drogas passa a ser passível de prisão e assim surge o "tráfico de drogas". Na década de 1970, é a medicina que decidirá se a pessoa que porta drogas é doente (passível de tratamento), ou criminosa (passível de medidas penais). No que se refere ao uso de drogas pelos jovens, os de classe média eram levados para tratamento e os pobres para instituições corretivas e, assim, foi criado esse duplo criminoso-doente, cujo destino passa a ser forjado pela lógica da seletividade penal.

Aqueles que não possuem orçamento social são, de acordo com Wacquant (2003), o alvo da seletividade do sistema penal, pois são aqueles que formarão a maior parcela das populações carcerárias:

[...] a "guerra contra as drogas" é o leitmotiv do funcionamento da máquina mortífera. No Rio de Janeiro, a criminalização por drogas passa de cerca de $8 \%$ em 1968 e $16 \%$ em 1988 a quase $70 \%$ no ano 2000. Lá como cá, a clientela do sistema penal é recrutada no exército de jovens negros e/ ou pobres (ou quase negros de tão pobres), lançados à própria sorte nos ajustes econômicos que as colônias sofreram naquela que ficou conhecida como a "década perdida". A continuidade do fracasso retumbante das políticas criminais contra drogas só se explica na funcionalidade velada do gigantesco processo de criminalização 
gerado por ela. As prisões do mundo estão cheias de jovens "mulas", "aviões", "olheiros", "vapores", "gerentes" etc. (p. 11).

Assim, é possível compreender que, a partir do momento em que esse sujeito jovem, pobre, usuário de drogas e marginalizado socialmente é capturado pelo sistema judiciário, sobre ele são impostas medidas que fazem jus apenas à segurança pública da sociedade, que levam em consideração apenas a sua atuação no tráfico e ignoram sua necessidade (e direito) de atendimento pelos serviços de saúde.

A preocupação com o potencial de perigo que esses sujeitos apresentam para a sociedade também é duplicada, uma vez que, além de serem considerados traficantes; ou seja, criminosos, são também viciados em drogas.

O conceito de vício em seu uso habitual é apenas expressão do preconceito. $\mathrm{O}$ estigma que fortalece o círculo cínico no qual ele surge. E o sistema do preconceito é parte do mecanismo de controle no grande dispositivo de segurança de nossa sociedade. [...] O uso que fazemos do termo vício sempre sofre do limite moralista que nos salva pessoalmente condenando algum outro (Tiburi, \& Dias, 2013, p. 45 e 49).

Neste ponto do artigo, torna-se importante retomarmos uma questão. A partir do pensamento de Foucault (2010), no modelo grego, a lei levava em consideração se a ação era boa ou má, sendo o sujeito tomado por ela apenas a partir do momento em que ele aparece modificando esta ação, tornando-a má. Já no modelo cristão, era o sujeito que importava, se ele era bom ou mau, já que era a qualidade do sujeito que modificava a ação. No modelo grego, temos uma concepção circunstancial, pois o foco era a ação, que poderia variar. No modelo cristão, temos uma concepção essencialista, pois o foco recai sobre o sujeito que pratica a ação, não mais a ação em si. O que se coloca aqui, como um processo de subjetivação no modelo cristão, é uma prática que tem como fim a produção de um sujeito bom e obediente.

A partir disso, pode-se pensar como no decorrer dos anos o modelo judiciário foi se aproximando, cada vez mais, do modelo cristão citado. Por exemplo, no que se refere à ideia de potencial perigoso, termo muito utilizado por alguns operadores do direito para justificar as decisões em prol de um perpétuo vigiar a um determinado sujeito. O que nos leva a outro exemplo, o caso já citado de um jovem que é pego com determinada quantidade de droga e é considerado um traficante e, portanto, vai para uma UNEI para cumprir medida socioeducativa de internação, ou para uma Comunidade terapêutica para encontrar a salvação cristã e se afastar dos meios que antes o levavam até o uso de drogas. Nos dois casos, considera-se o sujeito, seja como um sujeito perigoso, ou com um potencial perigoso, e que deve ser afastado da sociedade por um tempo para que, nesse tempo, reflita sobre o mau que causou a ela e torne-se uma pessoa diferente. Ou seja, mantém-se aqui a ideia de uma reforma da alma, enquanto processo de subjetivação que incide sobre o sujeito, em que a obediência se torna uma ferramenta, um dispositivo fundamental para a comprovação dessa reforma subjetiva.

Eis a camuflagem de um problema social pelo manto da individualização da culpa e da imoralidade do uso de drogas como dispositivo que configura um indivíduo pobre como mau. Mas é apenas a partir do momento em que esse sujeito infringe a lei para manter o consumo de uma substância psicoativa ilícita que o Estado o apreende como criminoso-doente e tenta justificar a sua falha estrutural em termos de políticas de saúde preventivas com políticas de segurança encobertas de um discurso moralista/religioso de salvação pessoal, ou simplesmente adotando a prática higienista de afastamento do sujeito perigoso da sociedade.

Foucault (2012) fala sobre as relações entre a loucura e o crime, historicamente, e como isso levou a conceitualizar a periculosidade como uma junção de saberes jurídicos e saberes "psi".

Trata-se de uma loucura que só aparece na forma de crime, que é justificada pelo próprio ato criminoso, já que, em todos os casos, não há outro precedente que confirme a loucura. Assim, o sintoma dessa loucura, que é o uso de drogas, é o crime que é cometido em razão dela e que, na maior parte das vezes, é o tráfico.

\section{Pensar a (des)obediência como resistência do usuário de drogas pobre}

Ao traçar os circuitos dos jovens usuários de drogas que entram em conflito com a lei, é possível perceber que neles há vários entraves no que se refere ao acesso desses sujeitos às medidas de atenção à saúde e ao próprio uso de drogas. A começar pela apreensão desses jovens como traficantes e à sua consequente 
chegada à delegacia (nem sempre especializada para crianças e adolescentes, apesar de o ECA prever isso), onde são tratados como criminosos. Depois, comumente dirigidos para cumprimento de medida socioeducativa de internação, o que não é previsto pelo Estatuto da Criança e do Adolescente, já que a lei determina que as medidas de internação só devem ser utilizadas como último recurso e aplicadas em caso de uso de violência ou grave ameaça (Lei No 8.069, 1990).

Nas Unidades Educacionais ou Comunidades Terapêuticas, esses jovens permanecerão em restrição de liberdade, tendo a possibilidade da remissão da medida condicionada por fatores ligados a um suposto bom comportamento, que se resume a ações daquilo que Foucault (2010) entende por obediência às regras desses locais.

É possível perceber que esse modelo está presente na prática do sistema judiciário atual no caso dos jovens em conflito com a lei que são usuários de drogas primeiramente pela qualificação dos indivíduos de acordo com a "personalidade" (Lei № 8.069, 1990, p. 80), mostrando que esse sujeito, que é bom ou mau a priori, é que vai qualificar o ato infracional.

Ao utilizar a "personalidade" como determinante numa circunstância de remissão da medida ou de progressão de cumprimento de regime da pena (Constantino, Assis, \& Pinto, 2016), a legislação responsabiliza-se por um termo que abrange inúmeros significados, de forma que o termo acaba caindo em uma significação de senso comum e sendo usado para definir sujeitos "sem personalidade" ou "com personalidade forte", fora outros mais específicos como "personalidade criminosa", por exemplo, entre outros que podemos encontrar nos diversos documentos que compõem processos desses jovens. Ademais, a psicologização/psiquiatrização que frequentemente é acionada como dispositivo de patologição incide sobre o jovem quando uma autoridade pede a avaliação da "personalidade" para um psicólogo ou psiquiatra, pois já tudo isso determina, em princípio, um "desvio de conduta", ou como no segundo caso, uma patologização, e por meio disso concede ou não a liberdade ao sujeito, mostrando, mais uma vez, que o que está em questão não é a ação em si, mas quem o cometeu. Dessa forma, evidencia-se muito mais o quanto a obediência, o cumprimento das normas e o bom comportamento estão aliados à progressão da medida, por exemplo, e ao possível futuro que será dado aos jovens em questão.
No que tange à obediência, é possível perceber que a progressão da medida de internação para o meio aberto, por exemplo, só é feita em casos em que esses jovens apresentam um "bom comportamento", de acordo com as entrevistas feitas com os profissionais que os atendem nas redes (Scisleski, Concentino, \& Galeano, 2015). Somando isso tudo ao fato de que a maior parte dos jovens que são pegos portando drogas vai para estabelecimentos como Comunidades Terapêuticas, que geralmente têm planos de ação pautados em uma espécie de salvação religiosa, mas não têm o acompanhamento em termos de saúde. Ou seja, trata-se de uma medida totalmente arbitrária em relação ao que está posto na lei. Dessa forma, é possível problematizar essas relações que foram tecidas historicamente entre o modelo cristão e o modelo judiciário, tomando como ilustração o caso dos jovens usuários de drogas que entram em conflito com a lei. Percebemos um sistema de obediência que foi herdado do cristianismo e é posto em prática, frequentemente, nas instituições punitivas e no próprio sistema judiciário e, depois, nos espaços em que esses jovens são levados para cumprir medidas restritivas de liberdade.

Podemos dizer, então, que esses jovens, por suas trajetórias sociais, são impelidos a desobedecer e a cometer atos infracionais como forma de sobrevivência. No entanto, recebem como intervenção do Estado, frequentemente, não um acompanhamento que os possibilite sair do circuito penal-punitivo, mas, justamente, em seguida, são capturados por um sistema que coloca a obediência como dispositivo para a suavização ou remissão da medida socioeducativa de internação, por exemplo (Lei No 8.069, 1990).

Podemos entender, assim, o paradoxo dos circuitos forjados pelas políticas de segurança no que tange aos jovens usuários de droga que entram em conflito com a lei.

Então, eu creio que se tem aqui o centro, o coração disso que constitui o propósito da direção cristã e, a dizer a verdade, o objeto do curso deste ano. Tem-se lá o ponto em que se encontram misturadas, acopladas, articuladas uma sobre a outra, duas obrigações seguintes: obedecer tudo e nada esconder. Ou, ainda, encontram-se aqui ligados os princípios: "nada querer por si mesmo" e o princípio "tudo dizer de si mesmo". Tudo dizer de si mesmo, nada esconder; nada querer por si mesmo, obedecer em tudo: essa junção entre 
esses dois princípios é, eu creio, o coração não somente da instituição monástica cristã, mas de toda uma série de práticas e de dispositivos que vão informar aquilo que constitui a subjetividade cristã e, por consequência, a subjetividade ocidental (Foucault, 2010, p. 93-94).

Podemos pensar a lógica de valorização da obediência operando juntamente com a lógica da valorização dos discursos de verdade, tanto no cristianismo quanto nos trâmites jurídicos percorridos por esses jovens. De forma que esses circuitos acabam sendo mais regados pela lógica da verdade-obediência cristã, mesmo quando ela aparece acobertada pela burocracia da operacionalização daquilo que se concretiza nas jurisprudências e que é - não coincidentemente, porque estratégica como ação de governo dirigido à população jovem e pobre -, ações punitivas pela manutenção da ordem de uma segurança pública, ainda que seja diferente daquilo que é determinado por lei.

\section{Considerações finais}

A grande questão da (des)obediência colocada neste artigo refere-se às formas em que ela, juntamente com os discursos de verdade do sujeito, aparece como fator determinante que opera como um dispositivo que permite alargar ou reduzir o tentáculo da segurança pública imbricada na racionalidade jurídico-penal. Isso conota a forte presença dogmática cristã nas formas em que as vidas desses jovens são operacionalizadas e governadas. O impacto da obediência como dispositivo que estrategicamente produz efeitos na vida desses jovens incide também como um alargamento dos procedimentos punitivos e da lógica da segurança pública, forjando um processo de subjetivação que articula pressupostos cristãos e morais com o status jurídico e psicológico do sujeito. "Personalidade desviante", "bom comportamento na unidade", "personalidade rebelde" são discursos que se colam aos sujeitos, definindo-os, de modo a determinar formas de impedir ou de permitir uma progressão de medida, por exemplo.

Somos levados a pensar o caminho feito da invisibilidade perante o Estado até as medidas socioeducativas desse sujeito que, enquanto se enquadra em uma situação de vulnerabilidade, de uso frequente de drogas, não é tomado pelo judiciário e não recebe intervenções em sua vida. A partir do momento em que é atuante em um delito, principalmente de tráfico, ou seja, quando é capturado pelo dispositivo da (des)obediência, é tomado por esse sistema judiciário, reforçando, assim, as práticas de desinvestimento, de punição e de desproteção, a partir da captura pela lógica da segurança pública.

No entanto, quando o sujeito é capturado pela malha jurídica, a forma pela qual será tratado incide, especialmente em termos de uma juventude pobre, não sobre os seus atos, mas sobre quem ele é. O olhar jurídico atual, herança de uma velha gestação moral-cristã, operada pelo dispositivo da obediência permite gerir o sujeito a partir de uma essência do seu ser, alargando os tentáculos do sistema punitivo penal para além da medida socioeducativa de internação, uma vez que ele deverá ser permanentemente vigiado. Obedecer torna-se, assim, não mais uma virtude, mas um imperativo para a liberdade. Uma liberdade cerceada, uma liberdade neoliberal, portanto. Uma liberdade muito diferente, contudo, das vidas que resistem ao desobedecer, insistindo em afirmar-se.

\section{Referências}

Agamben, G. (2004). Estado de exceção. São Paulo, SP: Boitempo.

Agamben, G. (2009). O que é um dispositivo? E outros ensaios. Chapecó, SC: Argos.

Brasil. (2012). Conselho Nacional de Justiça. Programa de Justiça ao Jovem A execução das medidas socioeducativas de internação. Brasília, DF: o autor.

Brasil. (2006). Sistema Nacional de Políticas Públicas sobre drogas. Brasília, DF: Senado Federal.

Carvalho, S. (2008). Pena e garantias. Rio de Janeiro, RJ: Lumens-Juris.

Conselho Nacional do Ministério Público - CNMP. (2016). A visão do Ministério Público sobre o sistema prisional brasileiro - 2016. Brasília, DF: o autor. 
Constantino, P., Assis, S. G., \& Pinto, L. W. (2016). O impacto da prisao no estado de saude mental dos presos do estado do Rio de Janeiro. Ciência e Saúde Coletiva, 21(7), 2089-2099. https://doi.org/10.1590/141381232015217.01222016

Conselho Federal de Psicologia - CFP. (2015). CFP e CFESS se mostram contrários às comunidades terapêuticas. Brasília, DF: o autor.

Dreyfus, H., \& Rabinows, P. (2010). Michel Foucault: Uma trajetória filosófica. Rio de Janeiro, RJ: Forense Universitária.

Foucault, M. (1994). Ditsetécrits: 1954-1988 (Tome III : 1976-1979, Bibliothéque de Sciences Humaines). Paris: Broché.

Foucault, M. (2002). A verdade e as formas juridicas. Rio de Janeiro: Nau editora.

Foucault, M. (2005). Em defesa da sociedade. São Paulo, SP: Martins Fontes.

Foucault, M. (2008b). Segurança, território, população. São Paulo, SP: Martins Fontes.

Foucault, M. (2008a). Vigiar e punir. Petrópolis, RJ: Vozes.

Foucault, M. (2009). Microfísica do poder. São Paulo, SP: Graal.

Foucault, M. (2010). Do governo dos vivos: Curso dado no Collège de France, 1979-1980. São Paulo/Rio de Janeiro, RJ: Achiamé.

Foucault, M. (2012). Ditos e escritos V: Ética, Sexualidade \& Política. Rio de Janeiro, RJ: Forense Universitária.

Foucault, M. (2015). A sociedade Punitiva.Sao Paulo: Martins Fontes.

Joia, J. H. (2014). As tóxicas tramas da abstinência: compulsoriedades nas internações psiquiátricas de crianças e adolescentes em situação de vulnerabilidade social (dissertação de Mestrado). Faculdade de Psicologia, Pontifícia Universidade Católica de São Paulo, São Paulo, SP, Brasil.

Lei No 8.069, de 13 de julho de 1990. Dispõe sobre o Estatuto da Criança e do Adolescente e dá outras providências. Diário Oficial da União, 27 set. 1990.

Lei No 11.343, de 23 de agosto de 2006. Institui o Sistema Nacional de Políticas Públicas sobre Drogas - Sisnad; prescreve medidas para prevenção do uso indevido, atenção e reinserção social de usuários e dependentes de drogas; estabelece normas para repressão à produção não autorizada e ao tráfico ilícito de drogas; define crimes e dá outras providências. Diário Oficial da União, 24 ago. 2006

Mato Grosso do Sul. (2014). Comissão Permanente de Direitos Humanos da OAB/MS Ricardo Brandão. Relatório da visita in locoà Unidade Educacional Interna (UNEI) Dom Bosco. Campo Grande, MS: o autor.

Nascimento, M. L. (Org). (2002). Pivetes: A produção de infâncias desiguais. Rio de Janeiro, RJ: Oficina do Autor.

Rizzini, I., \& Pilotti, F. (2009). A arte de governar crianças: A história das políticas sociais, da legislação e da assistência à infância no Brasil (2a ed.). São Paulo, SP: Cortez.

Scisleski, A. \& Guareschi, N. (2011). Promete falar a verdade? Psicologia \& Sociedade, 23(2), 220-227. https://doi. org/10.1590/S0102-71822011000200002

Scisleski, A. C. C., Concentino, C. L. C., Galeano, G. (2015). Pensando as (im)políticas para juventudes e os (in)direitos (des)humanos. In: A. Scisleski, \& N. Guareschi, (Orgs.), Juventude, marginalidade social e Direitos Humanos: da psicologia às Políticas Públicas (pp. 176-195). Porto Alegre, RS: EDIPUCRS.

Scisleski, A. C. C., Silva, J. L. C., Galeano, G. B., Caetano, C. L. C., Bruno, B. S. (2013). Polícias de saúde: Quem tem medo de usuários de drogas? Revista Polis e Psique, 3(3): 106-124.

Scisleski, A. C. C., Reis, C., Hadler, O., Weigert, M. A. B., Guareschi, N. M. F. (2012). Juventude e pobreza: A construção de sujeitos potencialmente perigosos. Arquivos Brasileiros de Psicologia, 64(3), 19-34.

Tiburi, M. \& Dias, A. C. (2013). Sociedade fissurada: Para pensar as drogas e a banalidade do vício. Rio de Janeiro, RJ: Civilização Brasileira.

Trevizani, T. M. (2013). Camisa de força para menores: a patologização de crianças e adolescentes (Hospício São Pedro, 1884-1929) (Dissertaçao de mestrado). Universidade Federal do Rio Grande do Sul, Porto Alegre, RS, Brasil.

Wacquant, Loic. (2003). Punir os pobres: A nova gestão da miséria nos Estados Unidos. Rio de Janeiro, RJ: Revan. 
Zaffaroni, E. R.; Pierangeli, J. H. (2008). Manual de direito penal brasileiro: Parte geral. São Paulo, SP: Revista dos Tribunais.

Maria Eduarda Parizan Checa

Mestranda em Psicologia Clínica pela Pontifícia Universidade Católica de São Paulo Graduada em Psicologia pela Universidade Católica Dom Bosco, Campo Grande - MS. Brasil. E-mail: duda.checa@gmail.com.

(iD) https:// orcid.org/0000-0003-4712-6076

\section{Ana Lígia Saab Vitta}

Mestranda em Psicologia Clínica pela Pontifícia Universidade Católica de São Paulo (PUC-SP), São Paulo - SP. Brasil. Graduada em Psicologia pela Universidade Católica Dom Bosco, Campo Grande - MS. Brasil. E-mail: anasvitta@ outlook.com

(iD https:// orcid.org/0000-0002-9245-5111

\section{Luis Henrique da Silva Sousa}

Mestrando em Psicologia pela Universidade Católica Dom Bosco, Campo Grande - MS. Brasil. Graduado em Psicologia pela Universidade Federal do Mato Grosso do Sul, Campo Grande - MS. Brasil. E-mail: luis.henri.que@hotmail.com (iD https:// orcid.org/0000-0002-5295-5226

\section{Andrea Cristina Coelho Scisleski}

Graduação em Psicologia, Universidade Federal do Rio Grande do Sul. Mestrado em Psicologia Social e Institucional, Universidade Federal do Rio Grande do Sul. Doutorado em Psicologia, Pontifícia Universidade católica do Rio Grande do Sul. E-mail: ascisleski@yahoo.com.br

(iD https:// orcid.org/0000-0001-8387-0391

\section{Maria Júlia Dias}

Graduanda em Psicologia pela Universidade Católica Dom Bosco, Campo Grande - MS. Brasil. E-mail: mjdias.03@ gmail.com

(iD https:// orcid.org/0000-0003-1078-3697

Endereço para envio de correspondência:

R. Monte Alegre, 984 - Perdizes, São Paulo - SP, 05014-901, Brasil

Recebido 23/08/2018

Aprovado 24/08/2018

Received 08/23/2018

Approved 08/24/2018

Recibido 23/08/2018

Aceptado 24/08/2018 
Como citar: Checa, M. E. P., Vitta, A.L.S., Sousa, L. H. S., Scisleski, A. C. C., \& Dias, M. J. (2018). Desobediência, alargamento da punição e segurança pública: Jovens usuários de drogas em conflito com a lei. Psicologia: Ciência e Profissão, 38(n.spe.2), 252-264. https://doi.org/10.1590/1982-3703000212842

How to cite: Checa, M. E. P., Vitta, A.L.S., Sousa, L. H. S., Scisleski, A. C. C., \& Dias, M. J.. (2018). Disobedience, Punishment Widening and Public Security: Young Drug Users in Conflit with the Law. Psicologia: Ciência e Profissão, 38(n.spe.2), 252-264. https://doi.org/10.1590/1982-3703000212842

Cómo citar: Checa, M. E. P., Vitta, A.L.S., Sousa, L. H. S., Scisleski, A. C. C., \& Dias, M. J. (2018). Desobediencia, Ampliación de la Punición y Seguridad Pública: Jovenes Usuarios de Drogas en Conflicto con la Ley. Psicologia: Ciência e Profissão, 38(n.spe.2), 252-264. https://doi.org/10.1590/1982-3703000212842 